\title{
WAVE-NUMBER ANALYSIS OF ICE-FLOW MODELLING
}

\author{
(Abstract) \\ by \\ E. D. Waddington* \\ (Department of Geophysics and Astronomy, University of British Columbia, Vancouver, \\ British Columbia V6T 1W5, Canada)
}

\begin{abstract}
The response of glaciers and ice sheets to climate or sea-level forcing over a range of time scales must be calculated for several different climate variation studies. Most time-dependent iceflow modelling uses finite differences to solve the continuity equation. Any numerical scheme can be treated as a filter $f(x)$ whose input is the ice profile at time step $n$ and whose output is the ice profile at time step $(n+1)$. The physics of ice deformation is contained in $f(x)$. Employing the usual linearizations (e.g. Paterson 1981: 254), the filter $f(x)$ has a complex transfer function $F(k)$ in the wave-number domain. The standard 1 inear stability analys is is obtained by choosing time and space mesh intervals so that the modulus of $F(k)$ is never greater than unity. In addition, the modulus of $F(k)$ describes the rate of diffusion of wave disturbances, and the phase of $F(k)$ describes the propagation speed. The transfer functions for several finitedifference schemes are compared to an analytical solution. For given time and space mesh intervals, implicit schemes are more accurate than explicit
\end{abstract}

schemes. Schemes with a staggered grid for the flux calculations can model diffusion out to the highest wave number seen by the mesh. Non-staggered schemes do not attenuate these wave numbers; they require additional numerical smoothing to suppress nonlinear aliasing effects which arise at the high wave numbers regardless of the time step sizes. This smoothing must be restricted to wave numbers higher than those contributing to the ice-profile spectrum.

Large errors in amplitude and propagation speed can result even at low wave numbers from using time steps larger than the limit set by standard stability analysis, then smoothing out the resulting instability. In this case, the filter $f(x)$ based on the physics of deforming ice has been effectively replaced by an arbitrary low-pass smoothing filter with no physical significance.

\section{REFERENCE}

Paterson W S B 1981 The physics of glaciers.

Oxford etc, Pergamon Press

\section{THE EFFECT OF LAND-SEA DISTRIBUTION ON ICE-SHEET}

\section{FORMATION}

\author{
(Abstract) \\ by \\ Robert G. Watts \\ (Department of Mechanical Engineering, Tulane University, New Orleans, Louisiana 70118, \\ U.S.A.) \\ and M. Ehteshamul Hayder \\ (School of Aerospace and Mechanical Engineering, Princeton University, Princeton, \\ New Jersey 08540, U.S.A.)
}

\section{INT RODUCT ION}

The response of a simple ice-sheet model forced by a periodic change in the climate point (the distance from the poleward limit of land to the point where snow persists at sea-level year-round) exhibits a bifurcation when certain dimensionless parameters undergo realistic changes. These dimensionless parameters are related to the poleward 1 imit of continents as well as to the frequency of the climate point variation and other parameters. It is postulated that this bifurcation may be responsible for the initiation of large glacial cycles about $900 \mathrm{ka}$ BP, following smaller, higher frequency ice-sheet advances and retreats before that time (Watts and Hayder 1983). It seems clear that the latitudinal locations of continents can affect the formation of ice sheets through interaction with the seasonal cycle.

We present here some results that we recently obtained with a two-dimensional, seasonal, diffusive, energy-balance climate model with a mixed-layer ocean and simple continents. The model itself has been discussed by Hayder (unpublished) and Watts and Hayder (in press), and the interested reader is referred to those papers for details.

The results that we present here are mostly concerned with the effect on the model seasonal cycle of shifting land-sea distribution. The model was first run with the distribution shown in Figure 1 . There is 


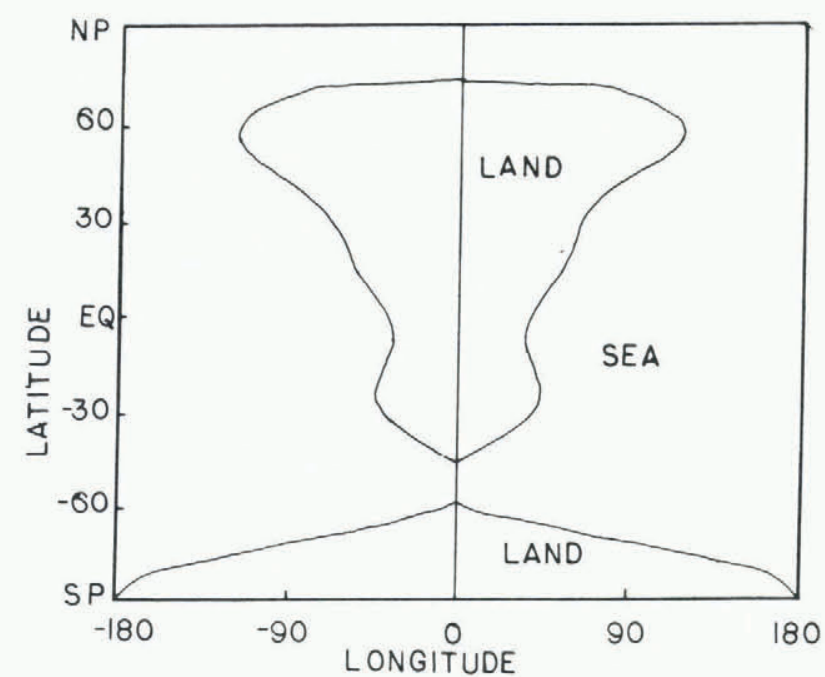

Fig.1. The "present" land-sea distribution used in the model.

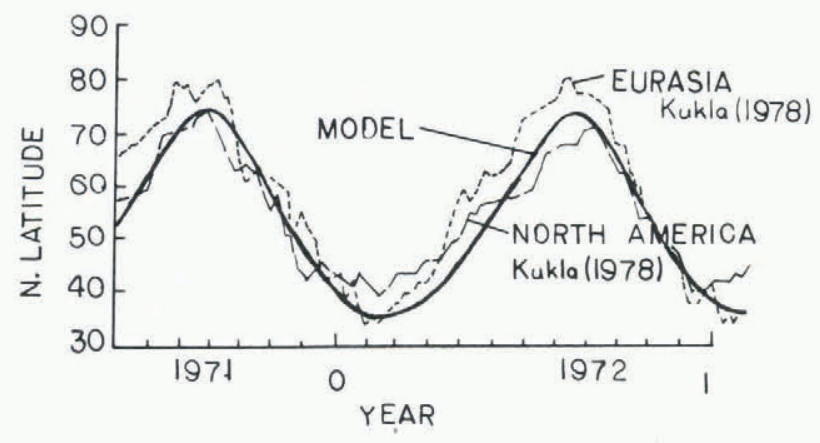

Fig.2. Snowline extent in the northern hemisphere.

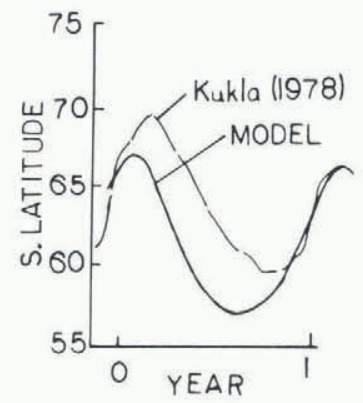

Fig.3. Sea-ice extent in the southern hemisphere.

a cluster of continents located along $0^{\circ}$ longitude. The land fraction shown corresponds closely to the present distribution of continents. Some representative seasonal data are shown in Figure 2 and Figure 3. Snow was assigned to land areas where the temperature was lower than $-1^{\circ} \mathrm{C}$ and sea ice where the surface temperature over the sea was lower than $-3.5^{\circ} \mathrm{C}$. Model results are compared with the data of Kukla (1978). Model parameters, such as diffusivities and albedos, are very near those in common use. Very little tuning of the model was necessary to produce an accurate seasonal cycle.

Next, we performed three experiments in which the model seasonal cycle was calculated for three different land fraction distributions. In the first case all the land is located in the southern hemisphere. The total land area is equal to the present area. Figure 4 shows the location of the snow and sea-ice limits as functions of season. The very large land fraction in the southern hemisphere leads to a very large seasonal cycle. Snow reaches $26^{\circ} \mathrm{S}$ latitude during the winter, but melts completely during midsummer. In Figure 5 the continent extends from the South Pole to the North Pole, but the land fraction in the southern hemisphere is still too large to permit snow to remain on the continent during the midsummer. With the land fraction distribution shown in Figure 6 , the seasonal cycle has become so small that snow remains on the continent in the southern hemisphere during the entire year.

We first point out that these are quite obviously very simple preliminary experiments from which we can draw only broad conclusions. It has of ten been suggested (e.g. Beaty 1978) that the formation of polar ice sheets requires large land masses at or near the poles. These experiments make it clear that this is a necessary condition, but not a sufficient one. If the land mass near the pole is too large, large seasonality does not permit the growth of ice sheets because the summers are too warm. It seems entirely possible that the absence of an Antarctic ice sheet before 30 to $50 \mathrm{Ma} B \mathrm{P}$ was at least partly due to the fact that the

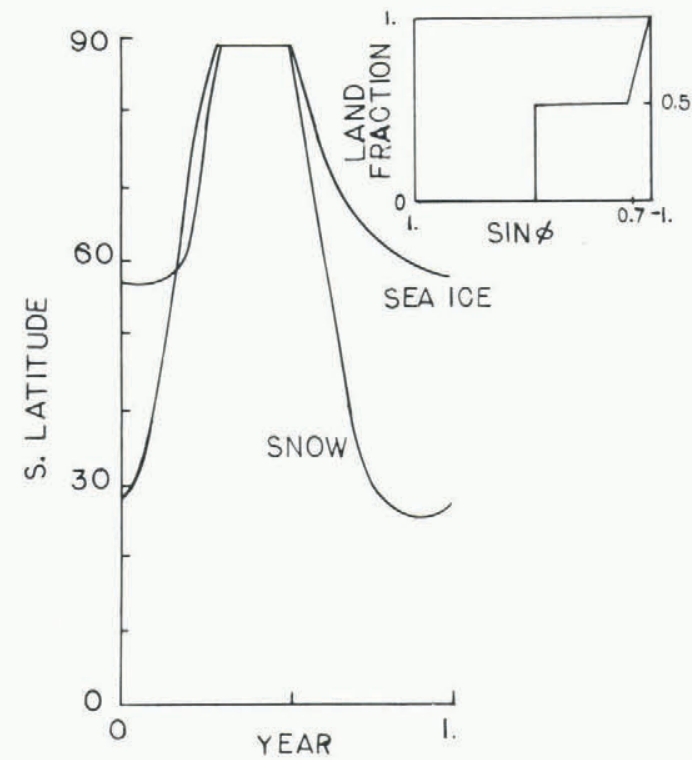

Fig.4. Snowline extent in the southern hemisphere as generated by the model.

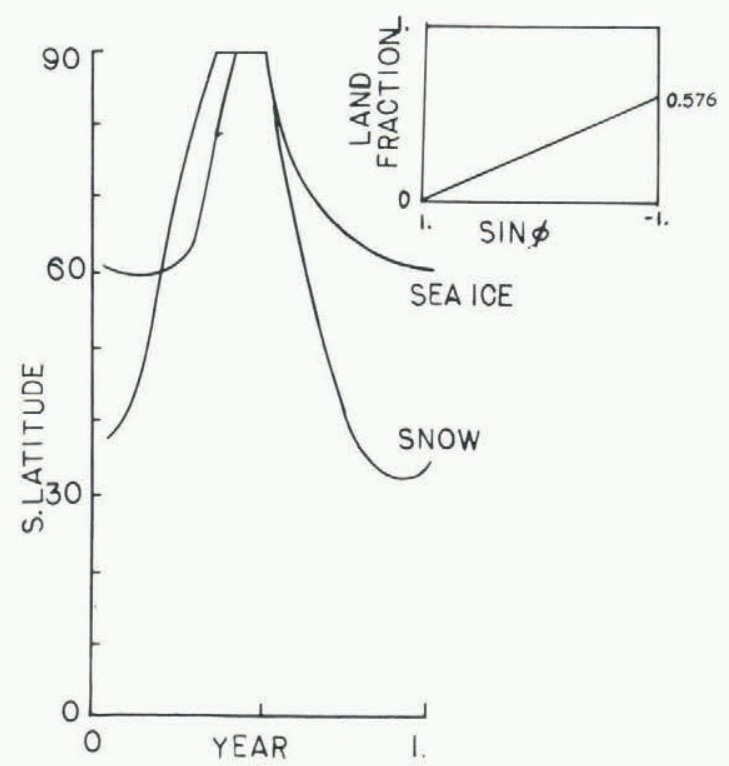

Fig.5. Snowline extent in the southern hemisphere as generated by the model. 


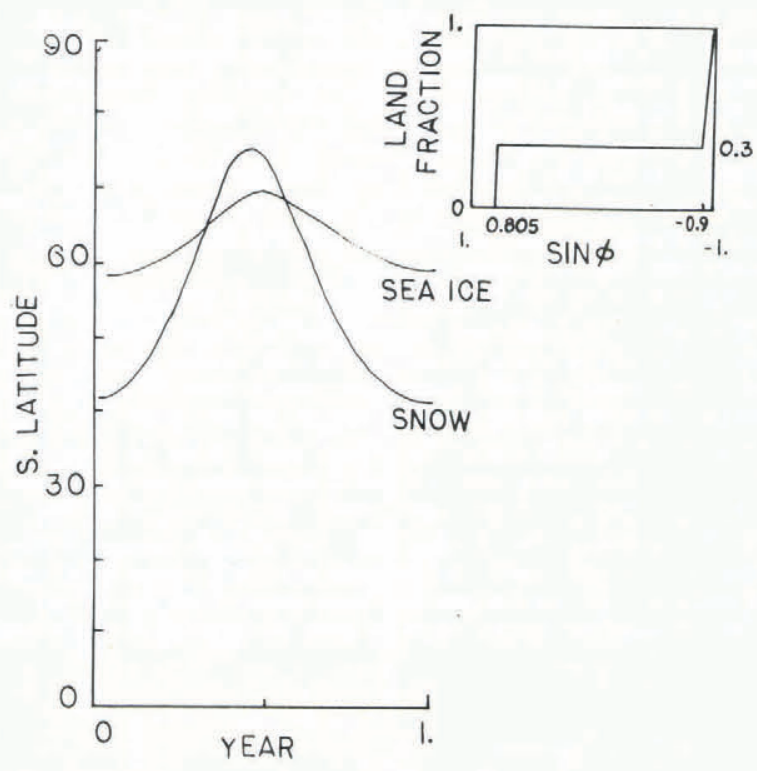

Fig.6. Snowline extent in the southern hemisphere as generated by the model.

land mass near the South Pole was too large to permit snow to remain on the ground for the entire year.

Shifting continentatl distributions must surely have been accompanied by changes in the circulation of the ocean, and, therefore, changes in the poleward advection of heat (Kvasov and Verbitsky 1981). In its present form, our model cannot account for this. It is certainly an important effect, and we are now modifying our model in such a way that we can include it. It seems clear that one result of including an increased poleward advective heat flux by the oceans, as suggested by Frakes and Kemp (1973), will be to increase the annual average temperature on the continent near the South Pole. This is consistent with the belief that polar climates were warmer during the Cretaceous.

Finally, we emphasize our main point. While a land mass must be close to a pole in order for an ice sheet to form (Watts and Hayder 1983, in press, Oerlemans in press) it seems possible for the land mass to be too large. (This is probably why the North American ice sheet formed before the Scandinavian ice sheet during the Quaternary ice age.) We conclude that a realistic model with which to study the initial formation of the Antarctic ice sheet 30 to $50 \mathrm{Ma}$ BP should contain a land-sea distribution and a seasonal cycle, as well as realistic poleward advection by ocean currents.

\section{ACKNOWLEDGEMENT}

We acknowledge support by the US National Science Foundation under grant ATM-7916332.

\section{REFERENCES}

Beaty B 1978 The causes of glaciation. American Scientist 66(4): 452-459

Frakes L A, Kemp E M 1973 Palaeogene continental positions and evolution of climate. In Tarling D H, Runcorn S K (eds) Implications of continental drift to the earth sciences. Vol 1: 539-559

Hayder ME Unpublished A two-dimensional, seasonal, energy balance climate model with continents and ice sheets: testing the Milankovitch theory of ice ages. (MS thesis, Tulane University, 1982)

Kukla G J 1978 Recent changes in snow and ice. In Gribbin J (ed) Climatic change. Cambridge etc, Cambridge University Press: 114-129

Kvasov D D, Verbitsky M Ya 1981 Causes of Antarctic glaciation in the Cenozoic. Quaternary Research 15(1): $1-17$

Oerlemans $\mathrm{J}$ In press On the origins of the ice ages. In Berger $A$, Imbrie J, Hays J, Kukla G, Saltzman B (eds) Milankovitch and climate: understanding the response to orbital forcing. Dordrecht, Reidel Pubilishing Co.

Watts R G, Hayder ME 1983 The origin of the 100kiloyear ice sheet cycle in the Pleistocene. Journal of Geophysical Research 88(9): 5163-5166

Watts R G, Hayder ME In press A two-dimensional, seasonal, energy-balance climate model with continents and ice sheets: testing the Milankovitch theory. Tellus

\section{A GLOBAL PALEOCLIMATIC DATABASE FOR 6 AND 9 ka BP}

\section{(Abstract)}

by

\section{Thompson Webb III}

(Department of Geological Sciences, Brown University, Providence, Rhode Island 02912-1846, U.S.A.)

A Cooperative Holocene Mapping Project (COHMAP) has assembled a database of Holocene paleoclimatic data from 1000 locations with ${ }^{14} \mathrm{C}$ dates (Table I). The data are stored on computer tapes at Brown University and will be available for verification of computer simulations of Holocene climates. Pollen, lake-level, and marine plankton data are the main sources of paleoclimatic information (Webb in press). Multivariate statistical techniques (Imbrie and Kipp 1971, Webb and Bryson 1972) and energy-budget models (Kutzbach 1980) exist that can transform each of these types of data into quantitative estimates of past temperature and precipitation.

Sites with pollen data are the most numerous ( 750 sites) with in the database (Table I), and dense networks of pollen sites exist in eastern North
America (Bernabo and Webb 1977), Europe (Huntley and Birks 1983), the Soviet Union (Peterson unpubl ished) and Alaska (Anderson unpubl ished). Pollen data from New Zealand, Africa, and South America are also being assembled. Work is now in progress to ga in climatic estimates from this pollen information, and Webb (in press) has presented maps of past temperatures and precipitation in the midwestern United States.

Lake-level data are the next most numerous source of Holocene paleoclimatic data (200 sites). Dense networks of sites exist in western North America, Africa and Australia (Street and Grove 1979). The changing lake levels directly record variations in the local water budget from which energy-budget and hydrological models can estimate past changes in precipitation (Kutzbach 1980). Water levels were 